OPEN ACCESS

Edited by:

Hans-Georg Breitinger,

German University in Cairo, Egypt

Reviewed by:

Li Zhang,

National Institutes of Health

United States

Timothy Lynagh,

University of Copenhagen, Denmark

Jean-Michel Rigo,

University of Hasselt, Belgium

*Correspondence: Robert J. Harvey r.j.harvey@ucl.ac.uk Joseph W. Lynch j.lynch@uq.edu.au Angelo Keramidas a.keramidas@uq.edu.au

Received: 27 February 2017 Accepted: 08 May 2017 Published: 23 May 2017

Citation:

Zhang Y, Ho TNT, Harvey RJ, Lynch JW and Keramidas A (2017) Structure-Function Analysis of the GlyR $\alpha 2$ Subunit Autism Mutation p.R323L Reveals a Gain-of-Function.

Front. Mol. Neurosci. 10:158. doi: 10.3389/fnmol.2017.00158

\section{Structure-Function Analysis of the GlyR $\alpha 2$ Subunit Autism Mutation p.R323L Reveals a Gain-of-Function}

\author{
Yan Zhang ${ }^{1}$, Thi Nhu Thao Ho ${ }^{1}$, Robert J. Harvey ${ }^{2 *}$, Joseph W. Lynch ${ }^{1,3 *}$ \\ and Angelo Keramidas ${ }^{1 *}$
}

${ }^{1}$ Queensland Brain Institute, The University of Queensland, Brisbane, QLD, Australia, ${ }^{2}$ Department of Pharmacology, UCL School of Pharmacy, London, United Kingdom, ${ }^{3}$ School of Biomedical Sciences, The University of Queensland, Brisbane, QLD, Australia

Glycine receptors (GlyRs) containing the a2 subunit regulate cortical interneuron migration. Disruption of the GlyR a2 subunit gene (G/ra2) in mice leads to disrupted dorsal cortical progenitor homeostasis, leading to a depletion of projection neurons and moderate microcephaly in newborn mice. In humans, rare variants in GLRA2, which is located on the $\mathrm{X}$ chromosome, are associated with autism spectrum disorder (ASD) in the hemizygous state in males. These include a microdeletion (GLRA2 $\triangle$ ex8-9) and missense mutations in GLRA2 (p.N109S and p.R126Q) that impair cell-surface expression of GlyR $\alpha 2$, and either abolish or markedly reduce sensitivity to glycine. We report the functional characterization of a third missense variant in GLRA2 (p.R323L), associated with autism, macrocephaly, epilepsy and hypothyroidism in a female proband. Using heterosynapse and macroscopic current recording techniques, we reveal that GlyR $\alpha 2^{\mathrm{R} 323 \mathrm{~L}}$ exhibits reduced glycine sensitivity, but significantly increased inhibitory postsynaptic current (IPSC) rise and decay times. Site-directed mutagenesis revealed that the nature of the amino acid switch at position 323 is critical for impairment of GlyR function. Single-channel recordings revealed that the conductance of $\alpha 2^{\mathrm{R} 323 \mathrm{~L}} \beta$ channels was higher than $\alpha 2 \beta$ channels. Longer mean opening durations induced by p.R323L may be due to a change in the gating pathway that enhances the stability of the GlyR open state. The slower synaptic decay times, longer duration active periods and increase in conductance demonstrates that the GlyR $\alpha 2$ p.R323L mutation results in an overall gain of function, and that GlyR $\alpha 2$ mutations can be pathogenic in the heterozygous state in females.

\section{Keywords: autism spectrum disorder, epilepsy, glycine receptor, GLRA2, GlyR $\alpha 2$ subunit}

\section{INTRODUCTION}

Glycine receptors (GlyRs) are key members of a ligand-gated ion channel superfamily that includes nicotinic acetylcholine receptors (nAChRs), 5-hydroxytryptamine type-3 receptors (5- $\mathrm{HT}_{3} \mathrm{Rs}$ ) and $\gamma$-aminobutyric acid type-A receptors $\left(\mathrm{GABA}_{\mathrm{A}} \mathrm{Rs}\right)$. There are four GlyR $\alpha$ subunits $(\alpha 1-\alpha 4)$ and one $\beta$ subunit, that share a common topology: a large $\mathrm{N}$-terminal extracellular domain (ECD) that harbors the ligand-binding site and four transmembrane domains (M1-M4) connected by short intracellular (M1-M2) and extracellular (M2-M3) loops and a long intracellular loop connecting M3 to M4 (Lynch, 2009). GlyRs can be formed as homomers, consisting of $\alpha$ subunits 
only, or as heteromers comprising $\alpha$ and $\beta$ subunits in a $3 \alpha: 2 \beta$ or $2 \alpha: 3 \beta$ stoichiometry (Grudzinska et al., 2005; Durisic et al., 2012; Yang et al., 2012). Key biological roles of different GlyR isoforms have been revealed by the study of GlyR dysfunction in rodent models and human disease. For example, the major adult GlyR isoform consisting of $\alpha 1$ and $\beta$ GlyR subunits, has a major role in the control of spinal motor reflex circuits. Mutations in the genes encoding this GlyR subtype (GLRA1 and GLRB) cause startle disease, characterized by noise- or touch-induced non-epileptic seizures, excessive muscle stiffness and neonatal apnea episodes in cattle, mice and humans (Harvey et al., 2008; Bode and Lynch, 2014). Allelic variants of GLRB have also recently been associated with agoraphobic behavior, an increased startle response and fear network activation (Deckert et al., 2017).

By contrast, GlyR $\alpha 3$ subunit knockout mice have revealed a role for this subtype in central inflammatory pain sensitization (Harvey et al., 2004), rhythmic breathing (Manzke et al., 2010), ethanol intake, preference and taste aversion (Blednov et al., 2015) and auditory nerve function (Dlugaiczyk et al., 2016). The GlyR $\alpha 4$ subunit has been linked to neurotransmitter release in sympathetic neurons (Boehm et al., 1997; Harvey et al., 2000) but is thought to be a pseudogene in humans (Simon et al., 2004) due to a stop codon in GLRA4 exon 9, causing a protein truncation between membrane-spanning domains M3 and M4. Perhaps for this reason, no mouse knockout model currently exists.

The GlyR $\alpha 2$ subtype has previously been linked to roles in synaptogenesis (Kirsch and Betz, 1998; Levi et al., 1998), cell fate and paracrine transmitter release (Mangin et al., 2003) in the developing cortex and spinal cord (Flint et al., 1998; Scain et al., 2010). GlyR $\alpha 2$ is also pivotal in the modulation of ethanol intake, aversion and preference (Blednov et al., 2015), retinal photoreceptor development (Young and Cepko, 2004) and the control of receptive field surround in retinal ganglion cells (Nobles et al., 2012; Zhang C. et al., 2015). However, more recent studies using a novel Glra2 knockout line provided compelling evidence that extrasynaptic activation of GlyRs containing the $\alpha 2$ subunit in interneurons is vital for control of cortical tangential migration during embryogenesis (Avila et al., 2013). In Glra2 knockout mice, dorsal cortical progenitor homeostasis was disrupted (Avila et al., 2014) impairing the capacity of apical progenitors to generate basal progenitors. This resulted in a reduction of projection neurons in upper or deep layers of the cerebral cortex and moderate microcephaly in newborn Glra2 knockout mice (Avila et al., 2014). Somatosensory cortical neurons in Glra2 knockout mice also have more dendritic branches with an overall increase in total spine number. This results in disruption of the excitation/inhibition balance, with an overall increase network excitability and enhanced susceptibility to epileptic seizures (Morelli et al., 2017) as well as defects in long-term potentiation and object recognition memory (Pilorge et al., 2016).

The kinetic properties of homomeric $\alpha 2$ subunit GlyRs have been studied at the single-channel and macropatch levels (Mangin et al., 2003; Krashia et al., 2011). These studies reveal that wild-type homomeric $\alpha 2$ GlyRs activate for longer durations than $\alpha 1$-containing GlyRs (Krashia et al., 2011) and activate and deactivate more slowly on an ensemble macropatch level (Mangin et al., 2003). Changes in GlyR subunit mRNA levels suggest a developmental switch in expression from predominantly $\alpha 2$ in embryonic/neonatal rodents to $\alpha 1 / \alpha 3$ in juveniles/adults, whereas expression of the $\beta$ subunit remains high throughout this period of development. Coupled with the observation that synaptic current decay is relatively slow in neonatal neurons and accelerates in neurons of juvenile rodents, it is reasonable to infer a developmental switch from $\alpha 2$ homomers or $\alpha 2 \beta$ heteromers to heteromeric $\alpha 1 \beta$ or $\alpha 3 \beta$ GlyRs (Singer et al., 1998).

Consistent with these findings, microdeletions and missense mutations in the human GlyR $\alpha 2$ subunit gene (GLRA2), which is located on the X-chromosome, have been associated with rare cases of autism spectrum disorder (ASD) in the hemizygous state in males (Pinto et al., 2010; Piton et al., 2011; Iossifov et al., 2014; Pilorge et al., 2016). To date, a microdeletion (GLRA2 $\triangle \mathrm{ex} 8-9)$ and two de novo missense mutations p.N109S and p.R126Q (p.N136S and p.R153Q in the GlyR $\alpha 2$ subunit with signal peptide) have been functionally characterized (Pilorge et al., 2016). GLRA2 $\Delta$ ex8-9 resulted in the production of a truncated mRNA that escaped nonsensemediated RNA decay. However, this resulted in a truncated GlyR $\alpha 2$ subunit protein lacking the third and fourth membranespanning domains and the cytoplasmic M3-M4 intracellular loop. Functional studies revealed that GlyR $\alpha 2^{\Delta \operatorname{ex} 8-9}$ was not expressed at the cell surface in $\mathrm{CHO}$ cells (Pilorge et al., 2016). By contrast, the GlyR $\alpha 2^{\mathrm{N} 109 \mathrm{~S}}$ and $\alpha 2^{\mathrm{R} 126 \mathrm{Q}}$ mutations resulted in reduced cell-surface expression and substantially reduced glycine sensitivity by one-to-two orders of magnitude (Pilorge et al., 2016). These mutations were classified as lossof-function based on their impaired trafficking and inability to respond to physiological levels of glycine. The aim of this study was to functionally characterize a third missense variant in GLRA2, (p.R323L), where the pathomechanism was unclear since it was found in the heterozygous state in a female patient and inherited from an apparently healthy mother (Piton et al., 2011).

\section{MATERIALS AND METHODS}

\section{Cell Culture and Molecular Biology}

Expression constructs encoding the human GlyR $\alpha 2$ and $\beta$ subunits were combined in $1 \alpha: 50 \beta$ ratio (heterosynapse and macropatch recordings) or $1 \alpha: 100 \beta$ (single-channel recordings) and transfected into HEK293 cells via $\mathrm{Ca}^{2+}$ phosphate-DNA co-precipitation. This resulted in a high level of expression of heteromeric $\alpha 2 \beta$ GlyRs (Zhang Y. et al., 2015). For heterosynapse experiments, expression constructs for the mouse neuroligin 2A (NL2A) splice variant and rat gephyrin were co-transfected along with GlyR constructs to facilitate the formation of heterosynapses. Empty pEGFP or CD4 plasmid was also transfected as expression markers. Site-directed mutagenesis was performed using the QuikChange kit (Agilent), and the 
successful incorporation of mutations was confirmed by Sanger DNA sequencing. Mutation position in the GlyR $\alpha 2$ subunit is indicated using mature subunit numbering (i.e., after signal peptide cleavage).

\section{Heterosynapse Formation}

Primary cultures of spinal cord neurons were prepared as previously described (Dixon et al., 2015; Zhang Y. et al., 2015). E15 timed-pregnant rats were euthanized via $\mathrm{CO}_{2}$ inhalation in accordance with procedures approved by the University of Queensland Animal Ethics Committee. Cells were plated at a density of $\sim 80,000$ cells per $18 \mathrm{~mm}$ poly-D-lysine coated coverslip in DMEM medium with $10 \%(\mathrm{v} / \mathrm{v})$ foetal bovine serum. After $24 \mathrm{~h}$, the plating medium was changed to Neurobasal medium supplemented with 2\% (v/v) B27 and 1\% $(\mathrm{v} / \mathrm{v})$ GlutaMAX, and a second feed after 1 week replaced half of this medium. Neurons were grown for 1-4 weeks in vitro and heterosynaptic co-cultures were prepared by directly introducing transfected HEK293 cells onto the primary neuronal cultures 1-3 days prior to recording.

\section{Electrophysiology}

Whole-cell recordings were performed on transfected HEK293 cells in voltage-clamp mode using a HEKA EPC10 amplifier (HEKA Electronics, Lambrecht, Germany) and PATCHMASTER software (HEKA), at room temperature. Cells were placed in an external solution comprising (in $\mathrm{mM}$ ): $140 \mathrm{NaCl}, 5 \mathrm{KCl}, 2 \mathrm{CaCl}_{2}, 1 \mathrm{MgCl}_{2}, 10 \mathrm{HEPES}$ and $10 \mathrm{D}$-glucose, adjusted to $\mathrm{pH} 7.4$ with $\mathrm{NaOH}$. Patch pipettes $(1-3 \mathrm{M} \Omega$ resistance), were pulled from borosilicate glass (GC150F7.5, Harvard apparatus), and filled with an intracellular solution containing the following (in $\mathrm{mM}$ ): $145 \mathrm{CsCl}, 2 \mathrm{CaCl}_{2}$, $2 \mathrm{MgCl}_{2}, 10$ HEPES, 10 EGTA and $2 \mathrm{MgATP}$, adjusted to $\mathrm{pH} 7.4$ with $\mathrm{NaOH}$. Glycine-gated currents were recorded at a holding potential of $-40 \mathrm{mV}$, digitized at $4 \mathrm{kHz}$ and filtered at $10 \mathrm{kHz}$. For inhibitory postsynaptic current (IPSC) recordings, patch-pipette resistances were adjusted to 4-6 M $\Omega$ and filled with the same internal solution. Series resistance was routinely compensated to $60 \%$ of maximum and was monitored throughout the recording. Both spontaneous and action potential-evoked glycinergic IPSCs in HEK293 cells were recorded at a holding potential $-60 \mathrm{mV}$ and signals were digitally sampled at $10 \mathrm{kHz}$ and filtered at $4 \mathrm{kHz}$. As these IPSCs were completely abolished by $1 \mu \mathrm{M}$ tetrodotoxin (not shown), we infer they were induced by spontaneous action potentials.

Single-channel currents were recorded from outside-out excised patches at a clamped potential of $-70 \mathrm{mV}$. Glass electrodes were pulled from borosilicate glass (G150F-3; Warner Instruments), coated with a silicone elastomer (Sylgard-184; Dow Corning) and heat-polished to a final tip resistance of 8-15 M $\Omega$ when filled with an intracellular solution containing (in $\mathrm{mM}$ ) $145 \mathrm{CsCl}, 2 \mathrm{MgCl}_{2}, 2 \mathrm{CaCl}_{2}, 10$ HEPES and 5 EGTA, pH 7.4. Excised patches were directly perfused with extracellular solution by placing them in front of one barrel of a doublebarrelled glass tube. Single-channel currents were either recorded while the patch was exposed to extracellular solution (without added glycine) or elicited by exposing the patch continuously to glycine $(100 \mu \mathrm{M}$ or $3 \mathrm{mM})$ containing solution. Experiments were recorded using an Axopatch 200B amplifier (Molecular Devices), filtered at $5 \mathrm{kHz}$ and digitized at $20 \mathrm{kHz}$ using Clampex (pClamp 10, Molecular Devices) via a Digidata 1440A digitizer. The currents were filtered off-line at $3 \mathrm{kHz}$ for analysis.

Macropatch recordings were performed in the excised outside-out patch-clamp configuration. Patch pipettes were fire-polished to a resistance of approximately $10 \mathrm{M} \Omega$ and filled with the same internal solution. Macroscopic currents in outside-out patches pulled from transfected HEK293 cells were activated by brief $(<1 \mathrm{~ms})$ exposure to agonists using a piezoelectric translator (Siskiyou). The speed of the solution exchange system was regularly calibrated by rapidly switching the solution perfusing an open patch pipette between standard extracellular solution and an extracellular solution that had been diluted by $50 \%$ with distilled water. By monitoring the resulting pipette current, we were able to ensure that the solution perfusing the macropatch was completely exchanged within $200 \mu$ s (Dixon et al., 2014). Recordings were performed using a Multiclamp 700B amplifier and pClamp9 software (Molecular Devices), filtered at $4 \mathrm{kHz}$ and sampled at $10 \mathrm{kHz}$.

\section{Analysis}

Analyses of IPSC amplitudes, 10\%-90\% rise times, and weighted decay time constants were performed using Axograph (Axograph Scientific). Only cells with a stable series resistance of $<25 \mathrm{M} \Omega$ throughout the recording period were included in the analysis. Single peak IPSCs with amplitudes of at least three times above the background noise were detected using a semi-automated sliding template. Each detected event was visually inspected and only well-separated IPSCs with no inflections in the rising or decay phases were included. To calculate macroscopic current decay time constants, averaged macroscopic traces were fitted with double-exponential functions in Axograph X, and a weighted time constant was calculated from individual time constants $(\tau 1, \tau 2)$ and their relative amplitude (A1, A2) as follows: $\tau_{\text {weighted }}=(\tau 1 \times A 1+\tau 2 \times A 2) /(A 1+A 2)$. The averaged data from individual cells were then pooled to obtain group data. Statistical analysis, and plotting were performed with Prism 5 (GraphPad Software). The fitting of single Gaussian functions to IPSC amplitude and decay time constant distributions was also performed using Prism 5. All data are presented as mean \pm SEM. Student's unpaired $t$-tests or one-way ANOVAs, as appropriate, were employed for comparisons. For all tests, the number of asterisks corresponds to level of significance: ${ }^{*} p<0.05,{ }^{* *} p<0.01,{ }^{* * *} p<0.001$ and ${ }^{* * * *} p<0.0001$. Single-channel recordings were analyzed with pClamp 10 (Clampfit, Molecular Devices) or QuB software. Segments of single-channel activity separated by long periods of baseline were idealized into noise-free open and shut events using a temporal resolution of $70 \mu \mathrm{s}$. Single-channel activations were separated using a shut period $\left(t_{\text {crit }}\right)$ ranging between $6 \mathrm{~ms}$ and $30 \mathrm{~ms}$, however most of the $t_{\text {crit }}$ values were $<10 \mathrm{~ms}$. Group data form current-voltage experiments were fitted to a polynomial using Sigmaplot (Systat Software), from which 
reversal potential was obtained. Ohm's Law was used to find single-channel conductance $(\gamma)$, in which $V_{\text {hold }}$ is the holding potential $(-70 \mathrm{mV}), V_{\text {lip }}$ is the liquid junction potential $(4.7 \mathrm{mV}$ for the solutions used) and $V_{\text {rev }}$ is the reversal potential as follows: $\gamma=(i) /\left(V_{\text {hold }}-V_{\text {ljp }}-V_{\text {rev }}\right)$.

\section{RESULTS}

\section{GlyR $\alpha 2^{\mathrm{R} 323 \mathrm{~L}}$ Mutation Is Associated with Autism, Loss of Acquired Language, Seizures, Macrocephaly and Hypothyroidism}

Previously reported GLRA2 mutations associated with ASD include a microdeletion (GLRA2 $\Delta$ ex8-9; Pinto et al., 2010) and de novo missense mutations p.N109S (Iossifov et al., 2014) and p.R126Q (Pilorge et al., 2016) identified in the hemizygous state in males with non-syndromic autism. Additional clinical symptoms were noted in two of these individuals, including language delay with functional language and low average IQ (GLRA2 $\Delta$ ex8-9) and hyperactivity, severe language delay and tonic-clonic seizures (p.R126Q). These mutations were classified as loss of function based on impaired cell-surface expression of GlyR $\alpha 2$, and abolition (GLRA2 $\triangle$ ex8-9) or markedly reduced sensitivity to glycine (p.N109S and p.R126Q; Pilorge et al., 2016). These recessive mutations were not found to be disease causing in female carriers, due to the presence of a normal GLRA2 allele, and because GLRA2 escapes $\mathrm{X}$-inactivation in the vast majority of tissues including brain (Cotton et al., 2015). However, many mutations in the GlyR $\alpha 1$ subunit gene (GLRA1) that cause startle disease show dominant inheritance (Harvey et al., 2008; Bode and Lynch, 2014). We therefore decided to examine the functional effects of potentially pathogenic variants found in females. In particular, we focussed on p.R323L (p.R350L in the GlyR a2 subunit with signal peptide; c.1049G>T in NM_001118885). This missense mutation was previously reported in a female with ASD (Piton et al., 2011) that was predicted to be damaging by a number of software packages (including PolyPhen-2, SNPs\&GO, MutPred, PANTHER and SIFT; Pilorge et al., 2016). This mutation is also extremely rare, as it is not reported in the Genome Aggregation Database $\left(\right.$ gnomAD $^{1}$ ) currently comprising 126,216 exome sequences and 15,136 wholegenome sequences from unrelated individuals. The mutated arginine is located the large M3-M4 intracellular loop of the GlyR a2 subunit and is highly conserved among GlyR subunits (Figure 1A). Additional clinical symptoms reported in this case include loss of acquired words, seizures, mild motor developmental delay, macrocephaly and hypothyroidism (Gauthier, personal communication).

\section{Effects of the $\alpha 2^{\mathrm{R} 323 \mathrm{~L}}$ Mutation on GlyR Channel Properties}

To determine the functional effects of the GlyR $\alpha 2^{\mathrm{R} 323 \mathrm{~L}}$ mutation, we examined the potency of glycine in activating

\footnotetext{
${ }^{1}$ http://gnomad.broadinstitute.org/
}

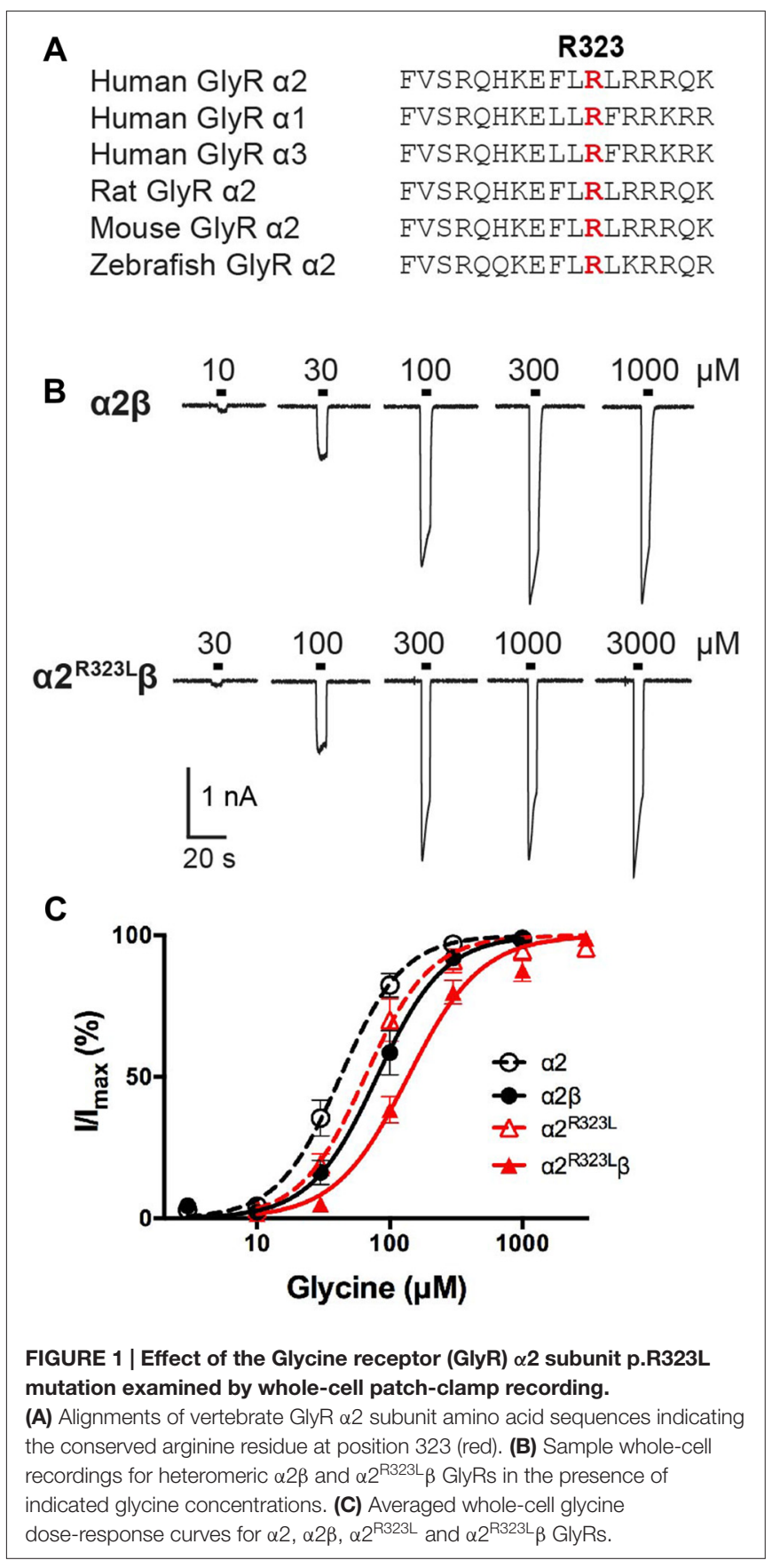

recombinant homomeric $\alpha 2^{\mathrm{R} 323 \mathrm{~L}}$ and heteromeric $\alpha 2^{\mathrm{R} 323 \mathrm{~L}} \beta$ receptors. Figure 1B illustrates whole-cell currents recorded in response to increasing concentrations of glycine in HEK293 cells expressing wild-type GlyRs or those containing $\alpha 2^{\mathrm{R} 323 \mathrm{~L}}$. The glycine dose-response curve of both homomeric $\alpha 2^{\mathrm{R} 323 \mathrm{~L}}$ and heteromeric $\alpha 2^{\mathrm{R} 323 \mathrm{~L}} \beta$ GlyRs were modestly right-shifted, with $\mathrm{EC}_{50}$ values of $67.9 \pm 13.4\left(\alpha 2^{\mathrm{R} 323 \mathrm{~L}}\right)$ and $143.0 \pm 12.9 \mu \mathrm{M}$ $\left(\alpha 2^{\mathrm{R} 323 \mathrm{~L}} \beta\right)$, compared with $46.6 \pm 6.7$ and $90.3 \pm 14.6 \mu \mathrm{M}$ for the corresponding wild-type $\alpha 2$ and $\alpha 2 \beta$ GlyRs (Table 1, Figure 1C). Thus, in both homomeric and heteromeric GlyRs, the p.R323L mutation results in a small decrease in apparent 
TABLE 1 | Summary of dose-response analysis data for $\alpha 2, \alpha 2 \beta, \alpha 2^{\mathrm{R} 323 \mathrm{~L}}$ and $\alpha 2^{\mathrm{R} 323 \mathrm{~L}} \beta$ Glycine receptors (GlyRs).

\begin{tabular}{lcccc}
\hline & $\boldsymbol{\alpha} \mathbf{2}$ & $\boldsymbol{\alpha} \mathbf{2} \boldsymbol{\beta}$ & $\boldsymbol{\alpha} \mathbf{2}^{\mathbf{R} 3 \mathbf{2 3 \mathbf { L }}}$ & $\boldsymbol{\alpha} \mathbf{2}^{\mathbf{R} \mathbf{2 3 \mathbf { L }}} \boldsymbol{\beta}$ \\
\hline EC $_{50} \boldsymbol{\mu M}$ & $46.6 \pm 6.7$ & $90.3 \pm 14.6$ & $67.9 \pm 13.4$ & $143.0 \pm 12.9^{*}$ \\
Hill slope & $2.2 \pm 0.1$ & $2.1 \pm 0.1$ & $2.1 \pm 0.2$ & $2.0 \pm 0.3$ \\
$I_{\max }(\mathrm{nA})$ & $1.6 \pm 0.2$ & $2.1 \pm 0.3$ & $1.5 \pm 0.4$ & $1.7 \pm 0.2$ \\
$n$ & 12 & 11 & 9 & 13
\end{tabular}

Statistical comparisons of $\alpha 2^{\mathrm{R} 323 \mathrm{~L}}$ and $\alpha 2^{\mathrm{R} 323 \mathrm{~L}} \beta$ were made relative to $\alpha 2$ and $\alpha 2 \beta$ GlyRs, respectively, via an unpaired Student's t-test. * $p<0.05$.

glycine sensitivity. There was no significant difference in peak whole-cell currents in all the receptors tested (range, $\sim 2-1.5 \mathrm{nA}$, Table 1) suggesting that mutations of R323 do not alter GlyR cell-surface expression.

\section{The GlyR $\alpha 2^{\mathrm{R} 323 \mathrm{~L}}$ Mutation Alters Intrinsic Channel Gating}

This modest change in dose-response relationship is insufficient to explain the pathogenic effects of the p.R323L mutation, especially since the peak glycine concentration in the synaptic cleft is thought to reach 1-3 $\mathrm{mM}$ in embryonic zebrafish neurons (Legendre, 1998) and 2.2-3.5 mM in adult rat spinal neurons (Beato, 2008). Clearance of glycine away from the cleft has also been estimated to occur on a $0.6-0.9 \mathrm{~ms}$ time scale (Beato, 2008). Based on these parameters, we examined intrinsic channel properties by rapidly applying saturating glycine $(3 \mathrm{mM})$ for a period of $\sim 1 \mathrm{~ms}$ to excised outside-out HEK293 cell patches expressing wild-type and mutant $\alpha 2^{\mathrm{R} 323 \mathrm{~L}} \beta$ receptors. Sample macroscopic currents are shown in Figure 2A. The time course of deactivation was fitted by a double exponential function with a mean time constant of $61.9 \pm 3.2 \mathrm{~ms}(n=15)$ for $\alpha 2 \beta$ GlyRs and a mean time constant of $87.9 \pm 5.4 \mathrm{~ms}(n=17)$ for $\alpha 2^{\mathrm{R} 323 \mathrm{~L}} \beta$ GlyRs (Figure 2B, Table 2). The deactivation time constant for $\alpha 2^{\mathrm{R} 323 \mathrm{~L}} \beta$ receptors was $\sim 1.5$-fold slower compared to wild-type GlyRs $(p<0.05)$. However, the rise time did not differ between wild-type and mutant receptors $\left(\alpha 2 \beta, 1.3 \pm 0.1 \mathrm{~ms} ; \alpha 2^{\mathrm{R} 323 \mathrm{~L}} \beta, 1.4 \pm 0.2 \mathrm{~ms} ; p>0.05\right)$.
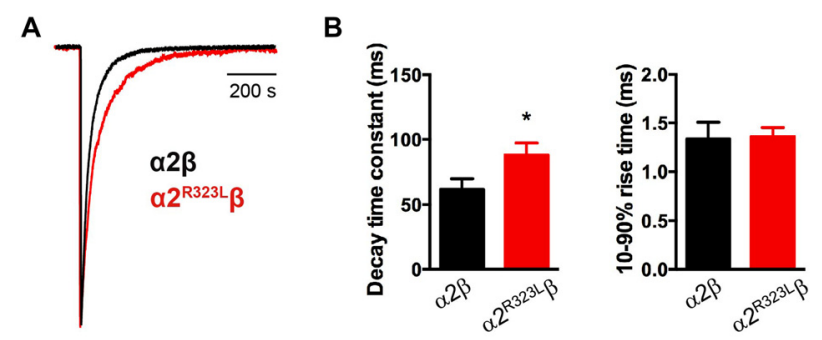

FIGURE 2 | Glycine-evoked $\alpha 2^{\mathrm{R} 323 \mathrm{~L}} \beta$ currents have slower intrinsic kinetic properties compared to wild-type $\alpha \mathbf{2} \beta$. (A) Averaged macropatch currents recorded from outside-out patches containing $\alpha 2 \beta$ (black trace) and $\alpha 2^{\mathrm{R} 323 \mathrm{~L}} \beta$ (red trace) GlyRs. Currents were activated by brief $(\sim 1 \mathrm{~ms})$ exposure to saturating (3 $\mathrm{mM}$ ) glycine. To allow comparison of kinetic properties, the currents were normalized to the same peak amplitude. (B) Comparison of mean macropatch current decay time constants and 10\%-90\% rise times. ${ }^{*} p<0.05$ relative to $\alpha 2 \beta$ GlyRs via unpaired Student's $t$-test.
This suggests that the p.R323L mutation in M3-M4 loop enhances channel function by slowing the channel closing rate. An analysis of the individual components of the double exponential fit revealed that the longer time constant and the fraction of the total current it represents increased (Table 3).

\section{The GlyR $\alpha 2^{\mathrm{R} 323 \mathrm{~L}}$ Mutation Alters Glycinergic IPSC Kinetics}

To test whether the enhancement of GlyR function altered glycinergic transmission, we used a heterosynapse system that allows control over the subunit composition of GlyRs in glycinergic synapses (Zhang Y. et al., 2015). We inserted $\alpha 2 \beta$ and $\alpha 2^{\mathrm{R} 323 \mathrm{~L}} \beta$ GlyRs into heterosynapses in turn to evaluate the properties of the resulting IPSCs. Sample IPSC recordings from heterosynapses incorporating $\alpha 2 \beta$ and $\alpha 2^{\mathrm{R} 323 \mathrm{~L}} \beta$ isoforms are shown at different temporal resolution in Figure $\mathbf{3 A}$ with averaged normalized IPSCs. The averaged IPSC amplitudes, $10 \%-90 \%$ rise times and decay time constants for $\alpha 2 \beta$ and $\alpha 2^{\mathrm{R} 323 \mathrm{~L}} \beta$ GlyRs are presented in Figure $3 \mathbf{B}$ and Table 2 . We observed that IPSCs mediated by $\alpha 2^{\mathrm{R} 323 \mathrm{~L}} \beta$ receptors displayed a 2 -fold slower rise and decay time than those mediated by wild-type $\alpha 2 \beta$ GlyRs (10\%-90\% rise time: $\alpha 2 \beta$, $2.6 \pm 0.3 \mathrm{~ms}, n=7 ; \alpha 2^{\mathrm{R} 323 \mathrm{~L}} \beta, 4.9 \pm 0.8 \mathrm{~ms}, n=6$, $p<0.01$; decay time: $\alpha 2 \beta, 27.0 \pm 1.5 \mathrm{~ms} ; \alpha 2^{\mathrm{R} 323 \mathrm{~L}} \beta$, $60.8 \pm 4.9 \mathrm{~ms}, p<0.0001$ ), whereas the mean IPSC amplitude did not differ significantly $\left(\alpha 2 \beta, 32.8 \pm 2.5 \mathrm{pA} ; \alpha 2^{\mathrm{R} 323 \mathrm{~L}} \beta\right.$, $34.0 \pm 11.9 \mathrm{pA} ; p>0.05)$. We also sought to investigate the effects of the previously described autism mutations, $\alpha 2^{\mathrm{N} 109 \mathrm{~S}}$ and $\alpha 2^{\mathrm{R} 126 \mathrm{Q}}$ (Pilorge et al., 2016), in heterosynapses, but heteromeric GlyRs incorporating these mutations yielded no detectable synaptic currents $(n>10$ cells expressing each mutant GlyR). This result was expected given that both mutations dramatically increased the glycine $\mathrm{EC}_{50}$ (Pilorge et al., 2016).

\section{The Nature of the Substitution at R323 Governs the Time-Course of Glycinergic IPSCs}

We next sought to investigate whether the nature of the side chain, charge or the steric characteristics of the p.R323L substitution contributes directly to the observed increase in intrinsic channel deactivation rates. Arginine is basic and polar (positively charged) with a 3-carbon aliphatic straight chain, capped at the distal end by a complex guanidinium group. We replaced $\mathrm{R} 323$ by alanine $\left(\alpha 2^{\mathrm{R} 323 \mathrm{~A}}\right)$ which is aliphatic, uncharged and has a short side chain consisting of a single methyl group. We also examined substitutions with lysine $\left(\alpha 2^{\mathrm{R} 323 \mathrm{~K}}\right.$, which is basic, and has a positively charged $\varepsilon$-amino group) and isoleucine $\left(\alpha 2^{\mathrm{R} 323 \mathrm{I}}\right.$, aliphatic, non-polar and differing from leucine only in the position of a side chain methyl group). We then characterized the effects of each GlyR $\alpha 2$ mutant on the kinetics of heterosynaptic IPSCs. Figure 3C shows sample recordings from heterosynapses incorporating the GlyR $\alpha 2^{\mathrm{R} 323 \mathrm{~A}}, \alpha 2^{\mathrm{R} 323 \mathrm{~K}}$ and $\alpha 2^{\mathrm{R} 323 \mathrm{I}}$ constructs, and averaged normalized IPSCs 


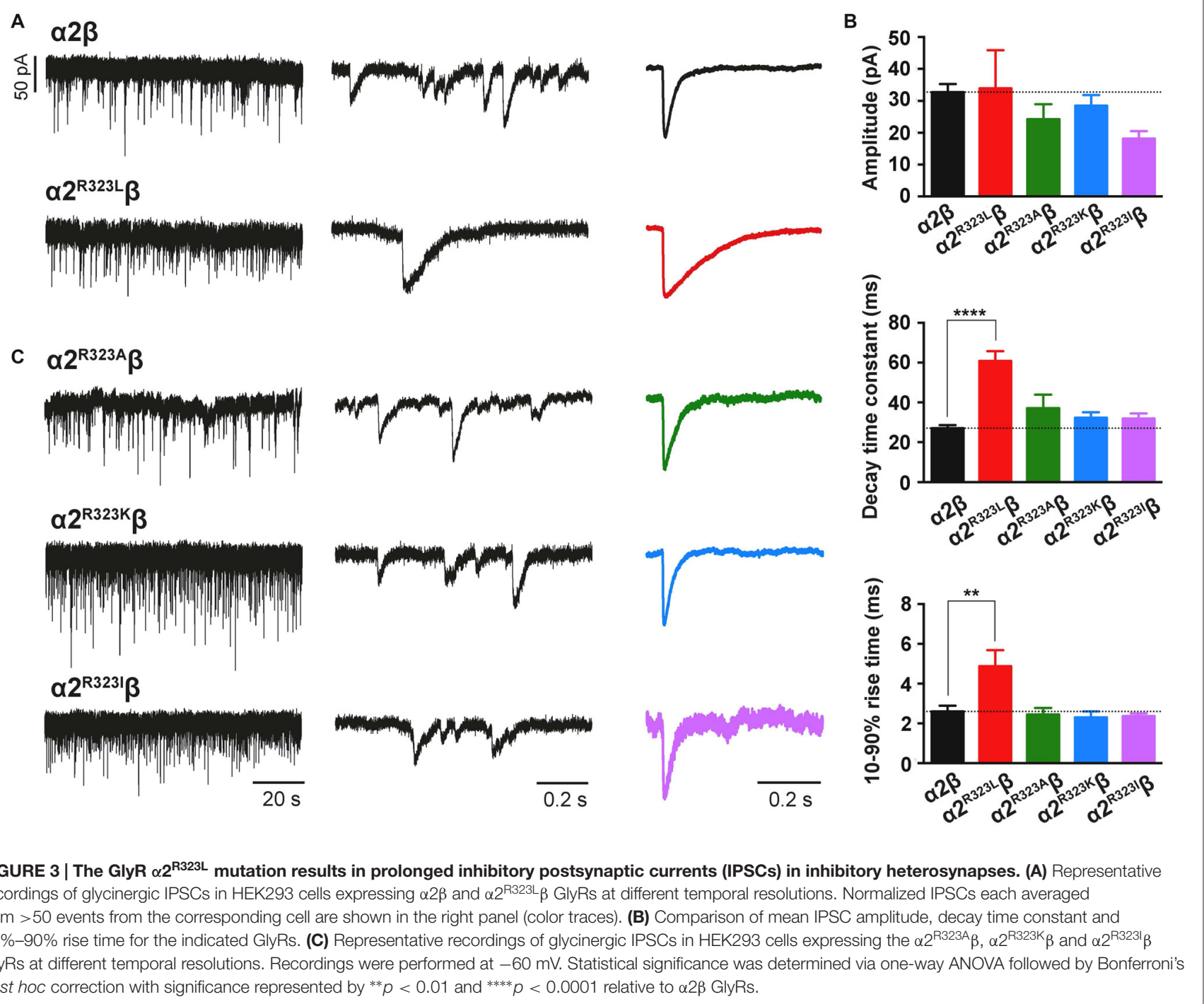

TABLE 2 | Comparison of 10\%-90\% rise times, decay time constants and maximal peak currents of inhibitory postsynaptic currents (IPSCs) and macropatch currents mediated by the wild type and mutant GlyRs.

\begin{tabular}{|c|c|c|c|c|c|c|}
\hline & & $\alpha 2 \beta$ & $\alpha 2^{\mathrm{R} 323 \mathrm{~L}} \beta$ & $\alpha 2^{\mathrm{R} 323 \mathrm{~A}} \beta$ & $\alpha 2^{\mathrm{R} 323 \mathrm{~K}_{\beta}}$ & $\alpha 2^{\mathrm{R} 3231} \beta$ \\
\hline \multirow[t]{2}{*}{$10 \%-90 \%$ rise time $(\mathrm{ms})$} & IPSCs & $2.6 \pm 0.3(7)$ & $4.9 \pm 0.8^{* *}(6)$ & $2.5 \pm 0.3(4)$ & $2.3 \pm 0.3(7)$ & $2.4 \pm 0.1(5)$ \\
\hline & macropatch currents & $1.4 \pm 0.1(17)$ & $1.3 \pm 0.2(15)$ & - & - & - \\
\hline \multirow[t]{2}{*}{ Deactivation time constant (ms) } & IPSCs & $27.0 \pm 1.5$ & $60.8 \pm 4.9^{* * * *}$ & $37.1 \pm 6.8$ & $32.3 \pm 2.8$ & $32.0 \pm 2.5$ \\
\hline & macropatch currents & $61.9 \pm 3.2$ & $87.9 \pm 5.4^{*}$ & - & - & - \\
\hline \multirow[t]{2}{*}{$I_{\max }(\mathrm{pA})$} & IPSCS & $32.8 \pm 2.5$ & $34.0 \pm 11.9$ & $24.3 \pm 4.7$ & $28.5 \pm 3.3$ & $18.2 \pm 2.0$ \\
\hline & macropatch currents & $381 \pm 47$ & $330 \pm 76$ & - & - & - \\
\hline
\end{tabular}

${ }^{*} p<0.05,{ }^{* *} p<0.01$ and ${ }^{* * * *} p<0.0001$ relative to the wild-type $\alpha 2 \beta$ GlyR, unpaired t-test for comparisons between two groups and one-way ANOVA followed by Bonferroni's post hoc correction for multiple comparisons. For IPSCs, $n$ values refer to the total number of cells from which data were collected. For each cell, parameters were analyzed from a single IPSC waveform that was digitally averaged from $>50$ individual events.

are presented in the right panel. All three substitutions produced heterosynaptic IPSCs that had kinetics similar to those of wild-type $\alpha 2 \beta$ GlyRs. Again, similar peak currents between mutant and wild-type receptors in macropatch and heterosynapse recordings suggests comparable surface expression (Table 2). 
TABLE 3 | Individual time constants and relative areas for macropatch currents.

\begin{tabular}{|c|c|c|c|c|c|}
\hline Receptor & $\tau 1(\mathrm{~ms})$ & A1 & $\tau 2$ (ms) & A2 & $n$ \\
\hline Wild-type $\alpha 2$ GlyR & $132 \pm 7$ & $0.29 \pm 0.03$ & $34.4 \pm 2.6$ & $0.71 \pm 0.03$ & 8 \\
\hline$\alpha 2^{\mathrm{R} 323 \mathrm{~L}} \beta$ G GlyR & $173 \pm 14^{*}$ & $0.37 \pm 0.03$ & $37.7 \pm 2.8$ & $0.63 \pm 0.02$ & 7 \\
\hline
\end{tabular}

Data represent mean $\pm S E M .{ }^{*} p<0.05$. The relative areas are expressed as a fractions.

\section{The GlyR $\alpha 2^{\mathrm{R} 323 \mathrm{~L}}$ Mutation Alters GlyR Single-Channel Kinetics}

Since another pathomechanism associated with GlyR mutations is spontaneously-opening channels (Chung et al.,
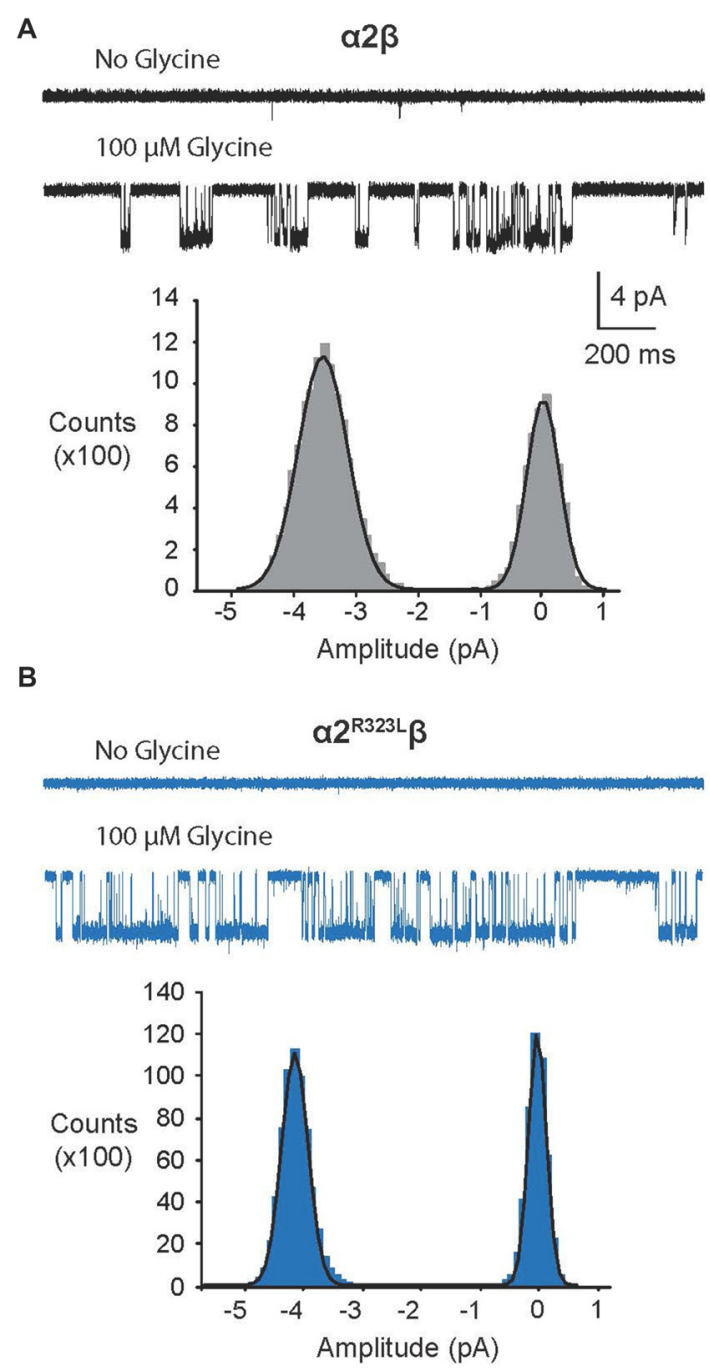

FIGURE 4 | Single-channel amplitude of heteromeric $\alpha 2 \beta$ and $\alpha 2^{\mathrm{R} 323 \mathrm{~L}} \beta$ GlyRs. (A,B) Both $\alpha 2 \beta$ and $\alpha 2^{\text {R323L }} \beta$ GlyRs showed no significant spontaneous activity in glycine-free solution (above). Activity in $\alpha 2 \beta$ and $\alpha 2^{\mathrm{R} 323 \mathrm{~L}} \beta$ receptors was observed in $100 \mu \mathrm{M}$ glycine solution (below). Amplitude histogram of $\alpha 2 \beta$ and $\alpha 2^{\mathrm{R} 323 \mathrm{~L}} \beta$ (bottom panels) revealed that the mutation produced a small but consistent increase in single-channel amplitude $\left(\alpha 2 \beta, \sim 3.2 \mathrm{pA}, \alpha 2^{\mathrm{R} 323 \mathrm{~L}} \beta \sim 3.8 \mathrm{pA}\right)$. Recordings were performed at $-70 \mathrm{mV}$ and channel openings are shown as downward deflections.
2010; Bode et al., 2013; James et al., 2013; Zhang et al., 2016), we examined the activity of $\alpha 2 \beta$ and $\alpha 2^{\mathrm{R} 323 \mathrm{~L}} \beta$ GlyRs in outside-out patches. No spontaneous activity was observed when patches containing $\alpha 2 \beta$ and $\alpha 2^{\mathrm{R} 323 \mathrm{~L}} \beta$ GlyRs were perfused with glycine-free solution for more than 1 min (Figures $\mathbf{4 A}, \mathbf{B}$ above). However, at a saturating $100 \mu \mathrm{M}$ glycine concentration, active periods were induced and observed as clusters of openings (Figures $4 \mathbf{A}, \mathbf{B}$ ). The current amplitude at $-70 \mathrm{mV}$ was determined for $\alpha 2 \beta$ and $\alpha 2^{\mathrm{R} 323 \mathrm{~L}} \beta$ GlyRs by plotting amplitude histograms and fitting these to Gaussian functions. GlyRs containing the $\alpha 2 \beta$ subunit combination displayed currents of $\sim 3.2 \mathrm{pA}$, whereas single-channel currents for $\alpha 2^{\mathrm{R} 323 \mathrm{~L}} \beta$ GlyRs were $\sim 3.8 \mathrm{pA}$ at $-70 \mathrm{mV}$ (Figures $4 \mathbf{A}, \mathbf{B}$ below). The singlechannel conductance was determined for both $\alpha 2 \beta$ and $\alpha 2^{\mathrm{R} 323 \mathrm{~L}} \beta$ GlyRs by carrying out current-voltage experiments over a range of voltages from $-70 \mathrm{mV}$ to $+70 \mathrm{mV}$ and averaged from three to five patches (Figures 5A,B). Mild inward rectification was observed in the current-voltage plots of both channels (Figures 5C,D). Current-voltage plots for heteromeric $\alpha 2 \beta$ and $\alpha 2^{\mathrm{R} 323 \mathrm{~L}} \beta$ GlyRs intersected the voltage axis at $\sim+3 \mathrm{mV}$ (Figure $5 \mathrm{C}$ ) and $\sim+5.5 \mathrm{mV}$ (Figure 5D), respectively. Mean single-channel conductance levels were calculated to be $41.2 \mathrm{pS}$ for $\alpha 2 \beta$ and $47.5 \mathrm{pS}$ for $\alpha 2^{\mathrm{R} 323 \mathrm{~L}} \beta$ and were statistically different $(p<0.05)$. Thus, the conductance of $\alpha 2^{\mathrm{R} 323 \mathrm{~L}} \beta$ GlyRs is slightly larger than that for wild-type $\alpha 2 \beta$ GlyRs, but less than that previously reported for homomeric $\alpha 2$ subunit GlyRs (60-120 pS; Wang et al., 2006; Krashia et al., 2011).

Finally, we investigated single-channel kinetics for $\alpha 2 \beta$ and $\alpha 2^{\mathrm{R} 323 \mathrm{~L}} \beta$ GlyRs. Samples of opening durations for $\alpha 2 \beta$ and $\alpha 2^{\mathrm{R} 323 \mathrm{~L}} \beta$ are shown in Figures $6 \mathrm{~A}, \mathbf{B}$, respectively. The duration of activations and open probabilities $\left(P_{\mathrm{o}}\right)$ for two channel types were assessed at $100 \mu \mathrm{M}$ and $3 \mathrm{mM}$ glycine (Table 4). At both concentrations, the mean duration of active periods for $\alpha 2^{\mathrm{R} 323 \mathrm{~L}} \beta$ GlyRs was longer than that observed for $\alpha 2 \beta$ GlyRs (Figure 6C). It is noteworthy that there was a high standard deviation in the values for wild-type $\alpha 2 \beta$ GlyRs at $3 \mathrm{mM}$ glycine. Although the $P_{\mathrm{o}}$ values of the two receptors were indistinguishable at $3 \mathrm{mM}$ glycine, at $100 \mu \mathrm{M}$ glycine $\alpha 2^{\mathrm{R} 323 \mathrm{~L}} \beta$ showed a significant increase in $P_{\mathrm{o}}$ compared to $\alpha 2 \beta$ (Figure 6D).

In summary, the increase in decay times for synaptic and macropatch currents, the small but significant increase in single-channel conductance and the prolongation of individual receptor active periods clearly demonstrates that overall, the R323L mutation confers a gain-offunction. 


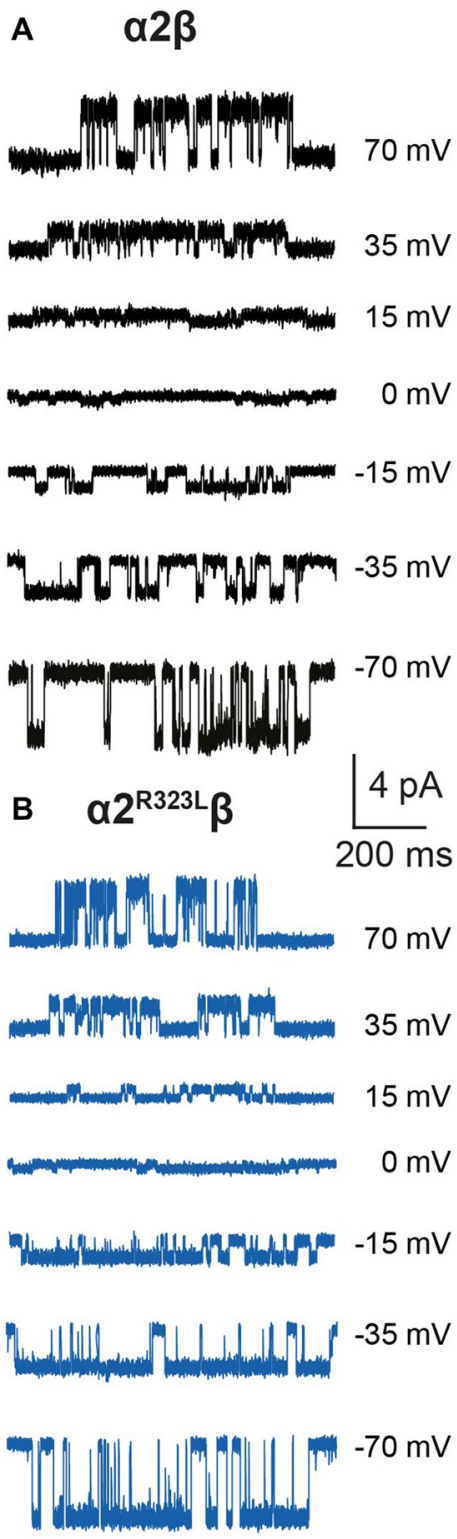

C $\quad \alpha 2 \beta$

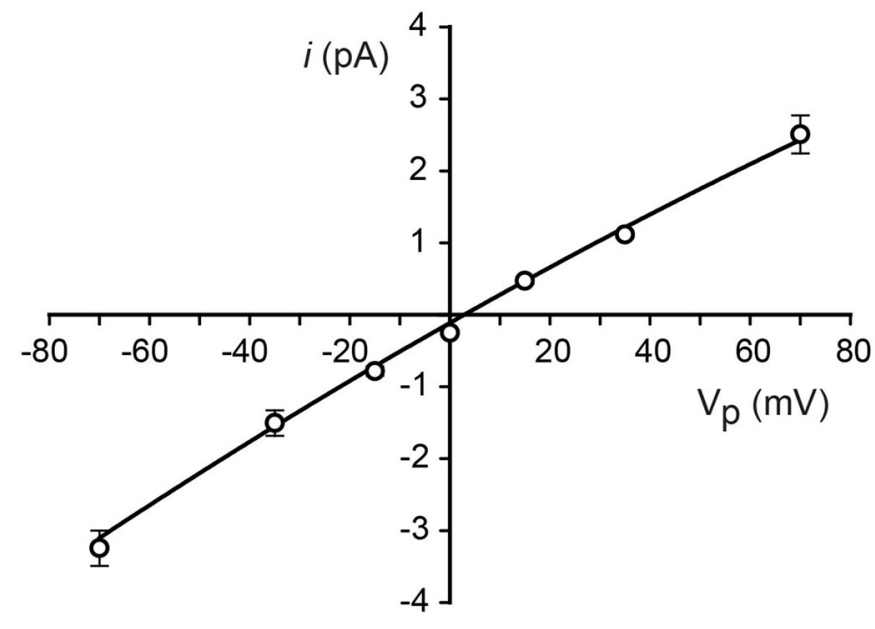

D
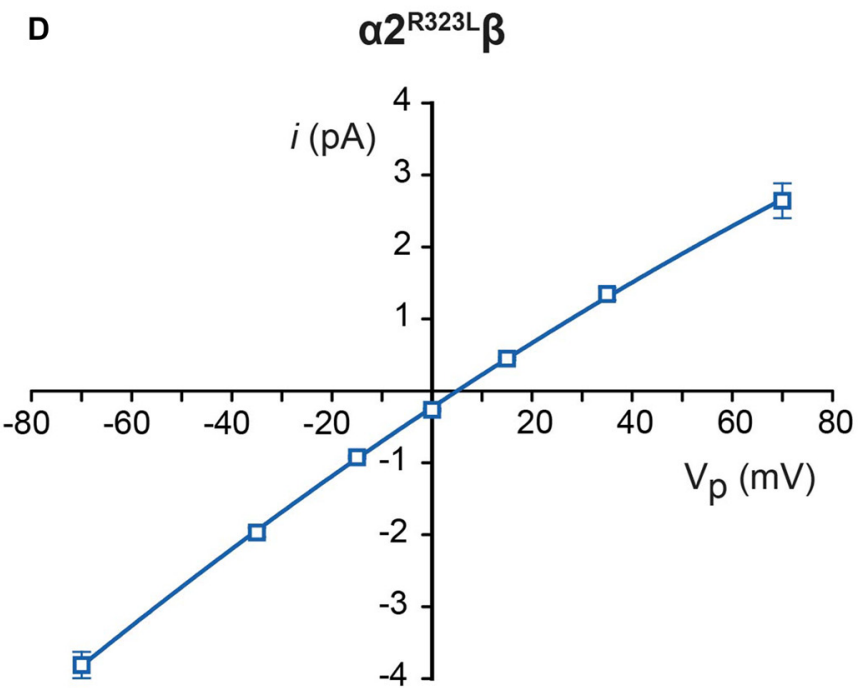

FIGURE 5 | Current-voltage and conductance characteristics of heteromeric $\alpha 2 \beta$ and $\alpha 2^{\mathrm{R} 323 \mathrm{~L}} \beta$ GlyRs. Sample currents obtained at the indicated pipette voltages for heteromeric $\alpha 2 \beta$ (A) and $\alpha 2^{\mathrm{R} 323 \mathrm{~L}} \beta$ GlyRs (B). Current-voltage relationships of heteromeric $\alpha 2 \beta$ (C) and $\alpha 2^{\mathrm{R} 323 \mathrm{~L}} \beta$ (D) GlyRs, obtained from averaged data from three to five patches.

TABLE 4 | Single-channel activation parameters of $\alpha 2 \beta$ and $\alpha 2^{\mathrm{R} 323 \mathrm{~L}} \beta$ receptors.

\begin{tabular}{|c|c|c|c|c|}
\hline \multirow[b]{2}{*}{ Channel } & \multicolumn{2}{|c|}{ Opening probabilities $\left(P_{0}\right)$} & \multicolumn{2}{|c|}{ Mean duration of active periods (ms) } \\
\hline & $100 \mu$ M glycine & $3 \mathrm{mM}$ glycine & $100 \mu \mathrm{M}$ glycine & $3 \mathrm{mM}$ glycine \\
\hline$\alpha 2 \beta$ & $0.73^{\#}$ & $0.76 \pm 0.02$ & $165 \pm 21$ & $242 \pm 102$ \\
\hline$\alpha 2^{\mathrm{R} 323 L_{\beta}}$ & $0.85 \pm 0.02$ & $0.82 \pm 0.02$ & $277 \pm 37^{*}$ & $360 \pm 44$ \\
\hline
\end{tabular}

Data represent mean $(n=3-4) \pm S E M .{ }^{*} p<0.05,{ }^{*}$ from $n=2$ patches.

\section{DISCUSSION}

We have described the detailed functional characterization of the GlyR $\alpha 2$ subunit p.R323L mutation associated with autism, macrocephaly, loss of acquired language, epilepsy and hypothyroidism. We used a combination of rapid glycine application, heterosynapses and single-channel recordings to quantify the intrinsic channel properties and IPSC kinetic 


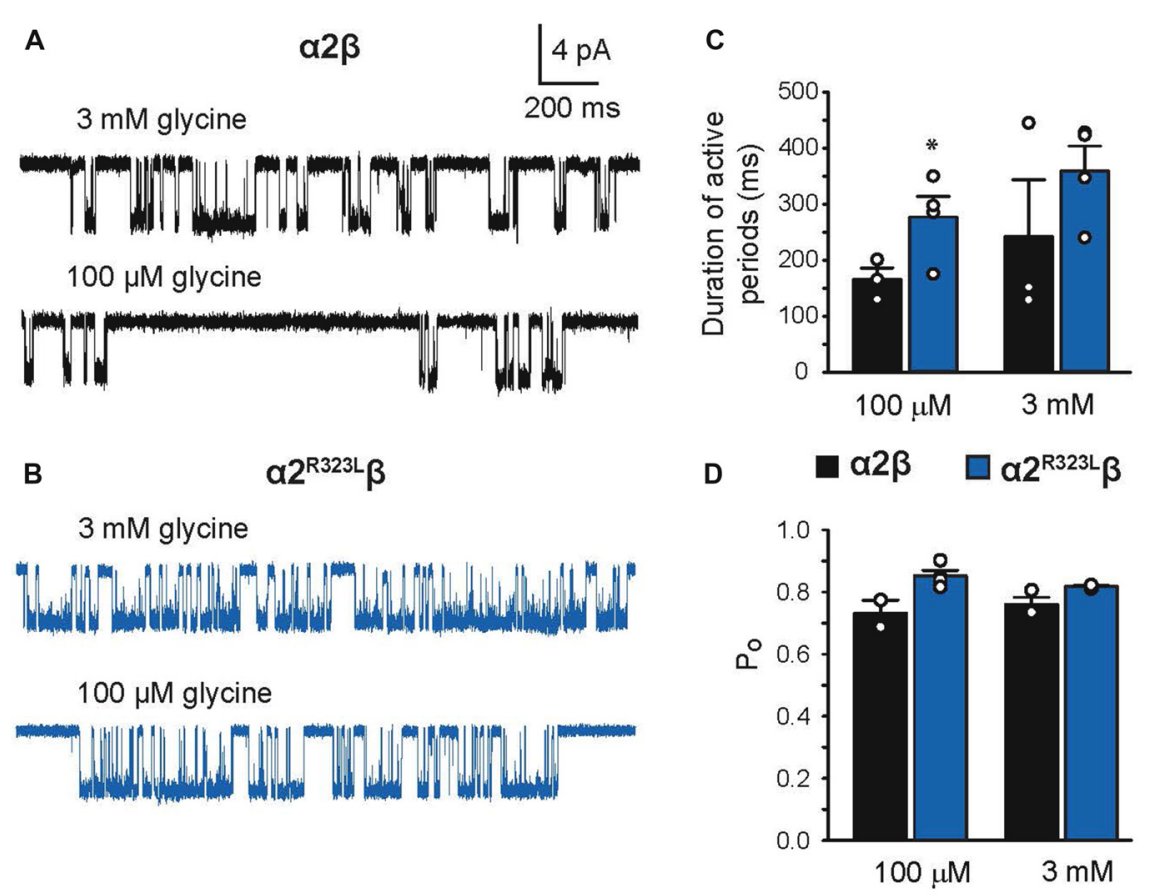

FIGURE 6 | Duration of single-channel activations in heteromeric $\alpha \mathbf{2} \boldsymbol{\beta}$ and $\alpha \mathbf{2}^{\mathrm{R} \mathbf{3 2 3 L}} \boldsymbol{\beta}$ GlyRs. Single-channel currents at the indicated concentrations of glycine for patches expressing heteromeric $\alpha 2 \beta$ (A) and $\alpha 2^{\text {R323L }} \beta$ GlyRs (B). Bar plots of the durations of active periods (C) and open probability (D) at the indicated glycine concentrations. Note that mutant $\alpha 2^{\mathrm{R} 323 \mathrm{~L}} \beta$ GlyRs activate in clusters with a longer opening duration compared to wild-type $\alpha 2 \beta$ GlyRs. ${ }^{*} p<0.05$.

properties of $\alpha 2^{\mathrm{R} 323 \mathrm{~L}} \beta$ GlyRs. We found that the p.R323L mutation resulted in a small apparent decrease in glycine sensitivity in $\alpha 2^{\mathrm{R} 323 \mathrm{~L}}$ and $\alpha 2^{\mathrm{R} 323 \mathrm{~L}} \beta$ GlyRs (Figure 1, Table 1). Notably, this was not of the same order of magnitude previously observed for the GlyR $\alpha 2^{\mathrm{N} 109 \mathrm{~S}}$ and $\alpha 2^{\mathrm{R} 126 \mathrm{Q}}$ loss-of-function mutations (Pilorge et al., 2016). Using outside-out patches, we found that the p.R323L mutation did not alter rise time, but slowed the deactivation time constant of $\alpha 2^{\mathrm{R} 323 \mathrm{~L}} \beta$ GlyRs by $\sim 1.5$ fold compared to wild-type $\alpha 2 \beta$ GlyRs (Figure 2, Table 2). We also examined properties of GlyR $\alpha 2^{\mathrm{R} 323 \mathrm{~L}} \beta$ GlyRs in glycinergic heterosynapses that were formed between presynaptic terminals of cultured spinal glycinergic interneurons and HEK293 cells expressing recombinant GlyRs. As well as allowing control over the subunit composition of the GlyRs under study, the electrotonically compact shape of HEK293 cells allows IPSC waveforms to be resolved with high fidelity (Dixon et al., 2015; Zhang Y. et al., 2015). IPSCs mediated by $\alpha 2^{\mathrm{R} 323 \mathrm{~L}} \beta$ receptors in heterosynapses displayed a 2 -fold slower rise and decay time than those mediated by wild-type $\alpha 2 \beta$ GlyRs, whereas the mean IPSC amplitude did not differ significantly (Figure 3, Table 3). As the change in IPSC decay rates corresponds well with the duration of single receptor active periods in the $\alpha 2^{\mathrm{R} 323 \mathrm{~L}} \beta$ receptors, we infer that the slower decay of IPSCs is dominated by the intrinsic gating properties of the channels. We next sought to understand whether the nature of the amino acid at position 323 is vital for the effect on ion channel function, replacing the basic and positively charged R323 by alanine (aliphatic, uncharged, short side chain), lysine (also basic and positively charged) and isoleucine (aliphatic, non-polar) and measuring the effects on heterosynaptic IPSCs. Surprisingly, all three substitutions resulted in GlyRs with wild-type characteristics (Figure 3, Table 2). This suggests that the bulky side chain at position R323 did not generate steric interactions with the adjacent GlyR subunits, and electrostatic mechanisms are not responsible for prolonged IPSC time courses observed in $\alpha 2^{\mathrm{R} 323 \mathrm{~L}} \beta$ GlyRs.

Finally, we examined the properties of $\alpha 2 \beta$ and $\alpha 2^{\mathrm{R} 323 \mathrm{~L}} \beta$ GlyRs using single-channel recordings (Figures 4-6), excluding the possibility that these mutant GlyRs resulted in spontaneously-opening channels, a known pathomechanism in startle disease involving GlyR $\alpha 1 \beta$ dysfunction (Chung et al., 2010; Bode et al., 2013; James et al., 2013; Zhang et al., 2016). Mean single-channel conductances were $41.2 \mathrm{pS}$ for $\alpha 2 \beta$ and $47.5 \mathrm{pS}$ for $\alpha 2^{\mathrm{R} 323 \mathrm{~L}} \beta$ (Table 3) suggesting that the conductance of $\alpha 2^{\mathrm{R} 323 \mathrm{~L}} \beta$ GlyRs is slightly, but significantly larger than that for wild-type $\alpha 2 \beta$ GlyRs. Moreover, the duration of activations and opening probability $\left(P_{\mathrm{O}}\right)$ at $100 \mu \mathrm{M}$ were also increased (Figure 6, Table 3), suggesting that $\alpha 2^{\mathrm{R} 323 \mathrm{~L}} \beta$ GlyRs spend more time in conducting states while active and were active for longer periods than wild-type $\alpha 2 \beta$ GlyRs. A single-channel study that examined $\alpha 2$ homomeric GlyRs concluded that these receptors exhibited longer active periods (mean open times) compared to adult synaptic $\alpha 1 \beta$ heteromeric GlyRs (Krashia et al., 2011). Another study that measured the duration of single-channel active periods estimated a mean duration of $\sim 500 \mathrm{~ms}$ for $\alpha 1 \beta$ heteromeric GlyRs, however, the active periods were isolated using longer shut periods $\left(t_{\text {crit }}\right)$ 
hGlyR a1S hGlyR a1L

hGlyR $\alpha 2$

hGlyR a3S

hGlyR a3L

a-helical

Portals

NLS

Topology

$\mathrm{G} \beta Y$

CB

$\mathrm{EtOH}$

PKC

PKA

Ub

Startle

hGlyR $\alpha 1 S$

hGlyR $\alpha 1 \mathrm{~L}$

hGlyR a2

hGlyR a3S

hGlyR a3L

a-helical

Portals

NLS

Topology

$\mathrm{G} \beta Y$

CB

$\mathrm{EtOH}$

PKC

PKA

Ub

Startle

RQHKELLRFRRKRRH ........... HKEDEAGEGRFNESAYGMGP

RQHKELLRFRRKRRHSPMLNLFQ . . . . HKEDEAGEGRFNFSAYGMGP R323L

RQHKEFLRLRRRQK.......... RQNKEEDVTRESRFNESGYGMGH

RQHKELLRFRRKRKNK........... DMDDEVRESRFSFTAYGMGP

RQHKELLRFRRKRKNKTEAFALEKFYRFSDMDDEVRESRFSFTAYGMGP

RQHKELLRFRRKRRHSPMLNLFQ..... HKEDEAGEGRFNESAYGMGP

RQHKELLRFRRKRRHSPMLNLFQ..... HKEDEAGEGRFNESAYGMGP

RQHKELLRFRRKRRHS PMLNLFQ..... HKEDEAGEGRFNFSAYGMGP

RQHKELLRFRRKRRHSPMLNLFQ . . . . HKEDEAGEGRFNFSAYGMGP

RQHKELLRFRRKRRHS PMLNLFQ . . . . HKEDEAGEGRFNFSAYGMGP

RQHKELLRFRRKRRHSPMLNLFQ . . . . . HKEDEAGEGRFNESAYGMGP

RQHKELLRFRRKRRHSPMLNLFQ . . . . HKEDEAGEGRFNFSAYGMGP

RQHKELLRFRRKRRHSPMLNLFQ . . . . HKEDEAGEGRFNESAYGMGP

RQHKELLRFRRKRKNKTEAFALEKFYRFSDMDDEVRESRFSFTAYGMGP

RQHKELLRFRRKRRHSPMLNLFQ...... HKEDEAGEGRFNFSAYGMGP

RQHKELLRFRRKRRHSPMLNLFQ......HKEDEAGEGRFNFSAYGMGP

R316X

G350S

ACLQAKDGISVKGANNSNTTNPPPAPSKSPEEMRKLFIQRAKKIDKISR

ACLQAKDGISVKGANNSNTTNPPPAPSKSPEEMRKLFIQRAKKIDKISR

. CLQVKDGTAVKATPANPLPQPP . . . KDGDAIKKKFVDRAKRIDTISR

. CLQAKDGMTPKGPNHPVQVMP . . . . KSPDEMRKVFIDRAKKIDTISR

. CLQAKDGMTPKGPNHPVQVMP . . . . KSPDEMRKVEIDRAKKIDTISR

ACLQAKDGISVKGANNSNTTNPPPAPSKSPEEMRKLFIQRAKKIDKISR

ACLQAKDGISVKGANNSNTTNPPPAPSKSPEEMRKLFIQRAKKIDKISR

ACLQAKDGISVKGANNSNTTNPPPAPSKSPEEMRKLFIQRAKKIDKISR

ACLQAKDGISVKGANNSNTTNPPPAPSKSPEEMRKLEIQRAKKIDKISR

ACLQAKDGISVKGANNSNTTNPPPAPSKSPEEMRKLFIQRAKKIDKISR

ACLQAKDGISVKGANNSNTTNPPPAPSKSPEEMRKLFIQRAKKIDKISR

ACLQAKDGISVKGANNSNTTNPPPAPSKSPEEMRKLFIQRAKKIDKISR

ACLQAKDGISVKGANNSNTTNPPPAPSKSPEEMRKLFIQRAKKIDKISR

. CLQAKDGMTPKGPNHPVQVMP . . . . KSPDEMRKVEIDRAKKIDTISR

ACLQAKDGISVKGANNSNTTNPPPAPSKSPEEMRKLFIQRAKKIDKISR

ACLQAKDGISVKGANNSNTTNPPPAPSKSPEEMRKLFIQRAKKIDKISR

E375X

D388A R392H

FIGURE 7 | Functionally-important residues and disease-causing mutations in GlyR intracellular loops. M3-M4 loop sequences of human GlyR $\alpha 1-\alpha 3$ subunits and alternatively spliced variants ( $\alpha 1 S, \alpha 1 \mathrm{~L}, \alpha 3 S$ and $\alpha 3 \mathrm{~L})$ are shown. Bold letters indicate residues that have been investigated in vitro for: structure ( $\alpha$-helical elements), ion permeation and desensitization (portals), nuclear localization signals (NLS), GlyR topology, binding of intracellular proteins (G $\beta \gamma$ ) or pharmacological agents such as cannabinoids (CB) and ethanol (EtOH), phosphorylation by PKC or PKA or ubiquitination (Ub). Mutations found in human patients with autism (GlyR $\alpha 2$ ) or startle disease (GlyR $\alpha 1$ ) are indicated in bold red type. Modified from Langlhofer and Villmann (2016).

(Scott et al., 2015). Taken together, these data strongly suggest that the p.R323L mutation results in an overall gain-of-function, although uniquely the resulting GlyRs do not show spontaneous channel openings. This may explain why this mutation is pathogenic even in the heterozygous state, and relates to some of the unique clinical features seen in this individual, including autism, macrocephaly and epilepsy. Autism has been associated with signs of cortical enlargement in children as young as 6 months of age and precedes brain overgrowth observed at 1-2 years of age (Hazlett et al., 2017). Autism, language delay and seizures have previously been associated with other human GlyR $\alpha 2$ mutations (Pilorge et al., 2016) and mouse models suggest that these features could arise from defects in cortical neuronal migration and/or dendritic branching, 
resulting in disrupted excitatory/inhibitory balance (Avila et al., 2013, 2014; Morelli et al., 2017). Given that loss-of-function of GlyR $\alpha 2$ leads to microcephaly in knockout mice (Avila et al., 2014), we speculate that the overall gain-of-function we observed for GlyR $\alpha 2^{\mathrm{R} 323 \mathrm{~L}}$ results in macrocephaly in the index patient.

One question that remains is why the p.R323L mutation is pathogenic in the index patient, but not in her mother, who is also a heterozygous carrier of the mutation. Here we note that although GlyR dysfunction has not previously been linked to hypothyroidism, this condition delays the development of the hyperpolarizing shift in the $\mathrm{Cl}^{-}$equilibrium potential during neuronal development, which in turn delays the maturation of GABAergic and glycinergic synaptic inhibition (Friauf et al., 2008). This is thought to explain the link between thyroid hormone deficiency and functional deficits in the nervous system (Friauf et al., 2008). Thus, one possibility is that the hypothyroidism in this patient could delaying the switch from excitatory to inhibitory synaptic transmission, thus exacerbating the effects of the GlyR $\alpha 2$ p.R323L mutation and prolonging the period of disrupted cortical neuronal migration. This hypothesis could be tested in future knock-in models for GlyR $\alpha 2^{\mathrm{R} 323 \mathrm{~L}}$ by measuring cortical neuronal migration and progenitor homeostasis, since hypothyroidism can be induced in animal models (Friauf et al., 2008).

Our study also underlines the importance of the GlyR intracellular M3-M4 loop in GlyR function (Langlhofer and Villmann, 2016). This region in GlyRs has been studied extensively (Figure 7). It is known to have $\alpha$-helical elements (Burgos et al., 2015) and is involved in phosphorylation (Harvey et al., 2004; Manzke et al., 2010; Han et al., 2013), intracellular sorting (Melzer et al., 2010), protein-protein interactions (Meyer et al., 1995; Melzer et al., 2010; Del Pino et al., 2014; Burgos et al., 2015), subunit topology (Sadtler et al., 2003) and modulation by $\mathrm{G} \beta \gamma$, ethanol and cannabinoids (CB; Yevenes et al., 2008; Yevenes and Zeilhofer, 2011; Burgos et al., 2015; Sanchez et al., 2015). Others have highlighted the importance of the GlyR M3-M4 intracellular loop in desensitization behavior (Nikolic et al., 1998), channel gating (Breitinger et al., 2009) and conductance (Carland et al., 2009). Of these, the GlyR $\alpha 2$ p.R323L substitution only overlaps with motifs involved in GlyR topology and/or G $\beta \gamma$ modulation in the GlyR $\alpha 1$ subunit. Since our data demonstrate that the GlyR $\alpha 2^{\mathrm{R} 323 \mathrm{~L}}$ reaches the membrane and is functional, it is unlikely that this mutation drastically affects GlyR topology. In addition, GlyR $\alpha 2$ is not modulated by G $\beta \gamma$ (Yevenes et al., 2010). Lastly, GlyR

\section{REFERENCES}

Avila, A., Vidal, P. M., Dear, T. N., Harvey, R. J., Rigo, J. M., and Nguyen, L. (2013). Glycine receptor $\alpha 2$ subunit activation promotes cortical interneuron migration. Cell Rep. 4, 738-750. doi: 10.1016/j.celrep. 2013.07.016

Avila, A., Vidal, P. M., Tielens, S., Morelli, G., Laguesse, S., Harvey, R. J., et al. (2014). Glycine receptors control the generation of projection neurons in the developing cerebral cortex. Cell Death Differ. 21, 1696-1708. doi: 10.1038/cdd. 2014.75 $\alpha 2$ p.R323L does not correspond to the position of any known startle disease missense mutation located in the M3-M4 loop (Figure 7), although a nonsense mutation (p.R316X) was reported (Tsai et al., 2004) at the same position in the GlyR $\alpha 1$ subunit. Given the effects of the GlyR $\alpha 2$ p.R323L mutation on channel conductance properties, intrinsic channel gating and IPSC kinetics, we suggest that this residue is a potential determinant of theoretical intracellular portals consisting of charged residues influencing ion permeation and conductance (Carland et al., 2009). Previously, these elements were thought to be localized at the $\mathrm{C}$-terminal end of the GlyR $\alpha 1$ subunit M3-M4 loop, where mutation of selected positively-charged residues (e.g., R377, K378, K385 and K386) to negativelycharged residues gave rise to non-functional channels (Carland et al., 2009). Our study provides new evidence suggesting that positively-charged residues at the $\mathrm{N}$-terminal end of the M3-M4 loop may have a key role to play in the control of IPSC rise and decay times, and mean channel opening durations.

\section{AUTHOR CONTRIBUTIONS}

JWL, RJH and AK designed the experiments; YZ, TNTH and AK performed the experiments; JWL, RJH and AK analyzed the data and wrote the article. All authors were involved in revising the article for important intellectual content, and gave final approval of the version to be published.

\section{FUNDING}

This work was supported by the National Health and Medical Research Council of Australia (1058542 to JWL), the Australian Research Council (DP150102428 to JWL) and the Medical Research Council (J004049, M013502 to RJH). The funders had no role in study design, data collection and analysis, decision to publish, or preparation of the manuscript.

\section{ACKNOWLEDGMENTS}

We thank Julie Gauthier (CHUM Research Center, Notre-Dame Hospital, Montreal, QC, Canada) and Guy A. Rouleau (Montreal Neurological Institute and Department of Neurology and Neurosurgery, McGill University, QC, Canada) for providing additional clinical information on the index case.

Blednov, Y. A., Benavidez, J. M., Black, M., Leiter, C. R., Osterndorff-Kahanek, E., and Harris, R. A. (2015). Glycine receptors containing $\alpha 2$ or $\alpha 3$ subunits regulate specific ethanol-mediated behaviors. J. Pharmacol. Exp. Ther. 353, 181-191. doi: 10.1124/jpet.114.221895

Bode, A., and Lynch, J. W. (2014). The impact of human hyperekplexia mutations on glycine receptor structure and function. Mol. Brain 7:2. doi: 10.1186/17566606-7-2 
Bode, A., Wood, S. E., Mullins, J. G., Keramidas, A., Cushion, T. D., Thomas, R. H., et al. (2013). New hyperekplexia mutations provide insight into glycine receptor assembly, trafficking, and activation mechanisms. J. Biol. Chem. 288, 33745-33759. doi: 10.1074/jbc.M113.509240

Boehm, S., Harvey, R. J., von Holst, A., Rohrer, H., and Betz, H. (1997). Glycine receptors in cultured chick sympathetic neurons are excitatory and trigger neurotransmitter release. J. Physiol. 504, 683-694. doi: 10.1111/j.1469-7793. 1997.683bd.x

Breitinger, H. G., Villmann, C., Melzer, N., Rennert, J., Breitinger, U., Schwarzinger, S., et al. (2009). Novel regulatory site within the TM3-4 loop of human recombinant $\alpha 3$ glycine receptors determines channel gating and domain structure. J. Biol. Chem. 284, 28624-28633. doi: 10.1074/jbc.M109. 043174

Burgos, C. F., Castro, P. A., Mariqueo, T., Bunster, M., Guzmán, L., and Aguayo, L. G. (2015). Evidence for $\alpha$-helices in the large intracellular domain mediating modulation of the $\alpha 1$-glycine receptor by ethanol and G $\beta \gamma$. J. Pharmacol. Exp. Ther. 352, 148-155. doi: 10.1124/jpet.114.217976

Carland, J. E., Cooper, M. A., Sugiharto, S., Jeong, H. J., Lewis, T. M., Barry, P. H., et al. (2009). Characterization of the effects of charged residues in the intracellular loop on ion permeation in $\alpha 1$ glycine receptor channels. J. Biol. Chem. 284, 2023-2030. doi: 10.1074/jbc.M806618200

Chung, S. K., Vanbellinghen, J. F., Mullins, J. G., Robinson, A., Hantke, J., Hammond, C. L., et al. (2010). Pathophysiological mechanisms of dominant and recessive GLRA1 mutations in hyperekplexia. J. Neurosci. 30, 9612-9620. doi: 10.1523/JNEUROSCI.1763-10.2010

Cotton, A. M., Price, E. M., Jones, M. J., Balaton, B. P., Kobor, M. S., and Brown, C. J. (2015). Landscape of DNA methylation on the X chromosome reflects $\mathrm{CpG}$ density, functional chromatin state and X-chromosome inactivation. Hum. Mol. Genet. 24, 1528-1539. doi: 10.1093/hmg/ddu564

Deckert, J., Weber, H., Villmann, C., Lonsdorf, T. B., Richter, J., Andreatta, M., et al. (2017). GLRB allelic variation associated with agoraphobic cognitions, increased startle response and fear network activation: a potential neurogenetic pathway to panic disorder. Mol. Psychiatry doi: 10.1038/mp.2017.2 [Epub ahead of print].

Del Pino, I., Koch, D., Schemm, R., Qualmann, B., Betz, H., and Paarmann, I. (2014). Proteomic analysis of glycine receptor $\beta$ subunit (GlyR $\beta$ )-interacting proteins: evidence for syndapin I regulating synaptic glycine receptors. J. Biol. Chem. 289, 11396-11409. doi: 10.1074/jbc.M113.504860

Dixon, C. L., Zhang, Y., and Lynch, J. W. (2015). Generation of functional inhibitory synapses incorporating defined combinations of $\mathrm{GABA}_{\mathrm{A}}$ or glycine receptor subunits. Cell Rep. 8:80. doi: 10.3389/fnmol.2015.00080

Dixon, C., Sah, P., Lynch, J. W., and Keramidas, A. (2014). GABA A receptor $\alpha$ and $\gamma$ subunits shape synaptic currents via different mechanisms. J. Biol. Chem. 289, 5399-5411. doi: 10.1074/jbc.M113.514695

Dlugaiczyk, J., Hecker, D., Neubert, C., Buerbank, S., Campanelli, D., Becker, C. M., et al. (2016). Loss of glycine receptors containing the $\alpha 3$ subunit compromises auditory nerve activity, but not outer hair cell function. Hear Res. 337, 25-34. doi: 10.1016/j.heares.2016.05.004

Durisic, N., Godin, A. G., Wever, C. M., Heyes, C. D., Lakadamyali, M., and Dent, J. A. (2012). Stoichiometry of the human glycine receptor revealed by direct subunit counting. J. Neurosci. 32, 12915-12920. doi: 10.1523/JNEUROSCI.2050-12.2012

Flint, A. C., Liu, X., and Kriegstein, A. R. (1998). Nonsynaptic glycine receptor activation during early neocortical development. Neuron 20, 43-53. doi: 10.1016/s0896-6273(00)80433-x

Friauf, E., Wenz, M., Oberhofer, M., Nothwang, H. G., Balakrishnan, V., Knipper, M., et al. (2008). Hypothyroidism impairs chloride homeostasis and onset of inhibitory neurotransmission in developing auditory brainstem and hippocampal neurons. Eur. J. Neurosci. 28, 2371-2380. doi: 10.1111/j.14609568.2008.06528.x

Grudzinska, J., Schemm, R., Haeger, S., Nicke, A., Schmalzing, G., Betz, H., et al. (2005). The $\beta$ subunit determines the ligand binding properties of synaptic glycine receptors. Neuron 45, 727-739. doi: 10.1016/j.neuron.2005.01.028

Han, L., Talwar, S., Wang, Q., Shan, Q., and Lynch, J. W. (2013). Phosphorylation of $\alpha 3$ glycine receptors induces a conformational change in the glycine-binding site. ACS Chem. Neurosci. 4, 1361-1370. doi: 10.1021/cn400097j
Harvey, R. J., Depner, U. B., Wassle, H., Ahmadi, S., Heindl, C., Reinold, H., et al. (2004). GlyR $\alpha 3$ : an essential target for spinal $\mathrm{PGE}_{2}$-mediated inflammatory pain sensitization. Science 304, 884-887. doi: 10.1126/science.1094925

Harvey, R. J., Schmieden, V., Von Holst, A., Laube, B., Rohrer, H., and Betz, H. (2000). Glycine receptors containing the $\alpha 4$ subunit in the embryonic sympathetic nervous system, spinal cord and male genital ridge. Eur. J. Neurosci. 12, 994-1001. doi: 10.1046/j.1460-9568.2000.00993.x

Harvey, R. J., Topf, M., Harvey, K., and Rees, M. I. (2008). The genetics of hyperekplexia: more than startle! Trends Genet. 24, 439-447. doi: 10.1016/j.tig. 2008.06.005

Hazlett, H. C., Gu, H., Munsell, B. C., Kim, S. H., Styner, M., Wolff, J. J., et al. (2017). Early brain development in infants at high risk for autism spectrum disorder. Nature 542, 348-351. doi: 10.1038/nature21369

Iossifov, I., O’Roak, B. J., Sanders, S. J., Ronemus, M., Krumm, N., Levy, D., et al. (2014). The contribution of de novo coding mutations to autism spectrum disorder. Nature 515, 216-221. doi: 10.1038/nature13908

James, V. M., Bode, A., Chung, S.-K., Gill, J. L., Nielsen, M., Cowan, F. M., et al. (2013). Novel missense mutations in the glycine receptor $\beta$ subunit gene (GLRB) in startle disease. Neurobiol. Dis. 52, 137-149. doi: 10.1016/j.nbd.2012. 12.001

Kirsch, J., and Betz, H. (1998). Glycine-receptor activation is required for receptor clustering in spinal neurons. Nature 392, 717-720. doi: 10.1038/33694

Krashia, P., Lape, R., Lodesani, F., Colquhoun, D., and Sivilotti, L. G. (2011). The long activations of $\alpha 2$ glycine channels can be described by a mechanism with reaction intermediates ("flip"). J. Gen. Physiol. 137, 197-216. doi: 10.1085/jgp. 201010521

Langlhofer, G., and Villmann, C. (2016). The intracellular loop of the glycine receptor: it's not all about the size. Front. Mol. Neurosci. 9:41. doi: $10.3389 /$ fnmol.2016.00041

Legendre, P. (1998). A reluctant gating mode of glycine receptor channels determines the time course of inhibitory miniature synaptic events in zebrafish hindbrain neurons. J. Neurosci. 18, 2856-2870.

Levi, S., Vannier, C., and Triller, A. (1998). Strychnine-sensitive stabilization of postsynaptic glycine receptor clusters. J. Cell Sci. 111, 335-345.

Lynch, J. W. (2009). Native glycine receptor subtypes and their physiological roles. Neuropharmacology 56, 303-309. doi: 10.1016/j.neuropharm.2008.07.034

Mangin, J. M., Baloul, M., Prado De Carvalho, L., Rogister, B., Rigo, J. M., and Legendre, P. (2003). Kinetic properties of the $\alpha 2$ homo-oligomeric glycine receptor impairs a proper synaptic functioning. J. Physiol. 553, 369-386. doi: 10.1113/jphysiol.2003.052142

Manzke, T., Niebert, M., Koch, U. R., Caley, A., Vogelgesang, S., Hulsmann, S., et al. (2010). Serotonin receptor 1A-modulated phosphorylation of glycine receptor $\alpha 3$ controls breathing in mice. J. Clin. Invest. 120, 4118-4128. doi: $10.1172 /$ JCI43029

Melzer, N., Villmann, C., Becker, K., Harvey, K., Harvey, R. J., Vogel, N., et al. (2010). Multifunctional basic motif in the glycine receptor intracellular domain induces subunit-specific sorting. J. Biol. Chem. 285, 3730-3739. doi: $10.1074 /$ jbc.m109.030460

Meyer, G., Kirsch, J., Betz, H., and Langosch, D. (1995). Identification of a gephyrin binding motif on the glycine receptor $\beta$ subunit. Neuron $15,563-572$. doi: 10.1016/0896-6273(95)90145-0

Morelli, G., Avila, A., Ravanidis, S., Aourz, N., Neve, R. L., Smolders, I., et al. (2017). Cerebral cortical circuitry formation requires functional glycine receptors. Cereb. Cortex 27, 1863-1877. doi: 10.1093/cercor/bhw025

Nikolic, Z., Laube, B., Weber, R. G., Lichter, P., Kioschis, P., Poustka, A., et al. (1998). The human glycine receptor subunit $\alpha 3$. GLRA3 gene structure, chromosomal localization and functional characterization of alternative transcripts. J. Biol. Chem. 273, 19708-19714. doi: 10.1074/jbc.273.31.19708

Nobles, R. D., Zhang, C., Muller, U., Betz, H., and McCall, M. A. (2012). Selective glycine receptor $\alpha 2$ subunit control of crossover inhibition between the on and off retinal pathways. J. Neurosci. 32, 3321-3332. doi: 10.1523/JNEUROSCI. 5341-11.2012

Pilorge, M., Fassier, C., Le Corronc, H., Potey, A., Bai, J., De Gois, S., et al. (2016). Genetic and functional analyses demonstrate a role for abnormal glycinergic signaling in autism. Mol. Psychiatry 21, 936-945. doi: 10.1038/mp. 2015.139 
Pinto, D., Pagnamenta, A. T., Klei, L., Anney, R., Merico, D., Regan, R., et al. (2010). Functional impact of global rare copy number variation in autism spectrum disorders. Nature 466, 368-372. doi: 10.1038/nature09146

Piton, A., Gauthier, J., Hamdan, F. F., Lafreniere, R. G., Yang, Y., Henrion, E., et al. (2011). Systematic resequencing of X-chromosome synaptic genes in autism spectrum disorder and schizophrenia. Mol. Psychiatry 16, 867-880. doi: $10.1038 / \mathrm{mp} .2010 .54$

Sadtler, S., Laube, B., Lashub, A., Nicke, A., Betz, H., and Schmalzing, G. (2003). A basic cluster determines topology of the cytoplasmic M3-M4 loop of the glycine receptor $\alpha 1$ subunit. J. Biol. Chem. 278, 16782-16790. doi: 10.1074/jbc. $\mathrm{m} 213077200$

Sanchez, A., Yevenes, G. E., San Martin, L., Burgos, C. F., Moraga-Cid, G., Harvey, R. J., et al. (2015). Control of ethanol sensitivity of the glycine receptor $\alpha 3$ subunit by transmembrane 2, the intracellular splice cassette and C-terminal domains. J. Pharmacol. Exp. Ther. 353, 80-90. doi: 10.1124/jpet.114.221143

Scain, A. L., Le Corronc, H., Allain, A. E., Muller, E., Rigo, J. M., Meyrand, P., et al. (2010). Glycine release from radial cells modulates the spontaneous activity and its propagation during early spinal cord development. J. Neurosci. 30, 390-403. doi: 10.1523/jneurosci.2115-09.2010

Scott, S., Lynch, J. W., and Keramidas, A. (2015). Correlating structural and energetic changes in glycine receptor activation. J. Biol. Chem. 290, 5621-5634. doi: 10.1074/jbc.m114.616573

Simon, J., Wakimoto, H., Fujita, N., Lalande, M., and Barnard, E. A. (2004). Analysis of the set of $\mathrm{GABA}_{\mathrm{A}}$ receptor genes in the human genome. J. Biol. Chem. 279, 41422-41435. doi: 10.1074/jbc.M401354200

Singer, J. H., Talley, E. M., Bayliss, D. A., and Berger, A. J. (1998). Development of glycinergic synaptic transmission to rat brain stem motoneurons. J. Neurophysiol. 80, 2608-2620.

Tsai, C. H., Chang, F. C., Su, Y. C., Tsai, F. J., Lu, M. K., Lee, C. C., et al. (2004). Two novel mutations of the glycine receptor gene in a Taiwanese hyperekplexia family. Neurol. 63, 893-896. doi: 10.1212/01.WNL.0000138566.65519.67

Wang, D. S., Mangin, J. M., Moonen, G., Rigo, J. M., and Legendre, P. (2006). Mechanisms for picrotoxin block of $\alpha 2$ homomeric glycine receptors. J. Biol. Chem. 281, 3841-3855. doi: 10.1074/jbc.m511022200

Yang, Z., Taran, E., Webb, T. I., and Lynch, J. W. (2012). Stoichiometry and subunit arrangement of $\alpha 1 \beta$ glycine receptors as determined by atomic force microscopy. Biochemistry 51, 5229-5231. doi: 10.1021/bi300063m
Yevenes, G. E., Moraga-Cid, G., Avila, A., Guzman, L., Figueroa, M., Peoples, R. W., et al. (2010). Molecular requirements for ethanol differential allosteric modulation of glycine receptors based on selective G $\beta \gamma$ modulation. J. Biol. Chem. 285, 30203-30213. doi: 10.1074/jbc.m110.134676

Yevenes, G. E., Moraga-Cid, G., Peoples, R. W., Schmalzing, G., and Aguayo, L. G. (2008). A selective $G \beta \gamma$-linked intracellular mechanism for modulation of a ligand-gated ion channel by ethanol. Proc. Natl. Acad. Sci. U S A 105, 20523-20528. doi: 10.1073/pnas.0806257105

Yevenes, G. E., and Zeilhofer, H. U. (2011). Molecular sites for the positive allosteric modulation of glycine receptors by endocannabinoids. PLoS One 6:e23886. doi: 10.1371/journal.pone.0023886

Young, T. L., and Cepko, C. L. (2004). A role for ligand-gated ion channels in rod photoreceptor development. Neuron 41, 867-879. doi: 10.1016/s08966273(04)00141-2

Zhang, Y., Bode, A., Nguyen, B., Keramidas, A., and Lynch, J. W. (2016). Investigating the mechanism by which gain-of-function mutations to the $\alpha 1$ glycine receptor cause hyperekplexia. J. Biol. Chem. 291, 15332-15341. doi: 10.1074/jbc.M116.728592

Zhang, Y., Dixon, C. L., Keramidas, A., and Lynch, J. W. (2015). Functional reconstitution of glycinergic synapses incorporating defined glycine receptor subunit combinations. Neuropharmacology 89, 391-397. doi: 10.1016/j. neuropharm.2014.10.026

Zhang, C., Nobles, R. D., and McCall, M. A. (2015). GlyR $\alpha 2$, not GlyR $\alpha 3$, modulates the receptive field surround of OFF retinal ganglion cells. Vis. Neurosci. 32:E026. doi: 10.1017/S0952523815000280

Conflict of Interest Statement: The authors declare that the research was conducted in the absence of any commercial or financial relationships that could be construed as a potential conflict of interest.

Copyright (C) 2017 Zhang, Ho, Harvey, Lynch and Keramidas. This is an open-access article distributed under the terms of the Creative Commons Attribution License (CC BY). The use, distribution or reproduction in other forums is permitted, provided the original author(s) or licensor are credited and that the original publication in this journal is cited, in accordance with accepted academic practice. No use, distribution or reproduction is permitted which does not comply with these terms. 